\title{
Activation of the FAK-src molecular scaffolds and p130Cas-JNK signaling cascades by $\alpha 1$-integrins during colon cancer cell invasion
}

\author{
SEVERINE VAN SLAMBROUCK ${ }^{1}$, CLARA GRIJELMO ${ }^{2}$, OLIVIER DE WEVER ${ }^{2,3}$, \\ ERIK BRUYNEEL ${ }^{2}$, SHAHIN EMAMI ${ }^{2}$, CHRISTIAN GESPACH ${ }^{2 *}$ and WIM F.A. STEELANT ${ }^{1 *}$ \\ ${ }^{1}$ Laboratory of Biochemical and Biomedical Research, Department of Chemistry, New Mexico Tech, Socorro, NM, USA; \\ ${ }^{2}$ INSERM U. 673, Université Pierre et Marie Curie-Paris 6, Faculté de Médecine, Laboratory of Molecular and Clinical \\ Oncology of Solid Tumors, Paris, France; ${ }^{3}$ Laboratory of Experimental Oncology, Department of \\ Radiotherapy and Nuclear Medicine, Ghent University Hospital, Ghent University, Belgium
}

Received May 4, 2007; Accepted June 27, 2007

\begin{abstract}
Increased src tyrosine kinase expression and activity has been associated with colon cancer cell invasion and survival. Several signaling pathways are involved in the oncogenic activation of src during the adenoma to carcinoma progression and cellular invasion. In the present study, the synthetic ether lipid analog ET-18-OMe was shown to promote invasion of HCT-8/S11 colon cancer cells into collagen type I through the concomitant activation of src by phosphorylation at Tyr416 (5-30 min) in $\alpha 1$-integrin immunoprecipitates containing the integrin binding proteins talin and paxillin, as well as the phoshorylated and activated forms of focal adhesion kinase (FAK) at Tyr397 (a FAK kinase activation signal), Tyr576 and Tyr861. This was associated with the lateral redistribution of $\alpha 1$-integrins in focal aggregates and persistent activation of the $\mathrm{p} 130 \mathrm{Cas} / \mathrm{JNK}$ pathways at 5$30 \mathrm{~min}$, with the subsequent induction and activation of the matrix metalloproteinases MMP-2 and MMP-9 (2-12 h). These activated molecular scaffolds and signaling cascades
\end{abstract}

Correspondence to: Dr Christian Gespach, INSERM U. 673, Université Pierre et Marie Curie-Paris 6, Faculté de Médecine, Laboratory of Molecular and Clinical Oncology of Solid Tumors, Hôpital Saint-Antoine, 75571 Paris 12, France

E-mail: christian.gespach@st-antoine.inserm.fr.

${ }^{*}$ Contributed equally

Abbreviations: ECL, enhanced chemiluminescence; ECM, extracellular matrix; ERK, extracellular signal-regulated kinase; FAK, focal adhesion kinase; GSL, glycosphingolipid; JNK, c-Jun $\mathrm{NH}_{2}$ terminal kinase; MAPK, mitogen-activated protein kinase; $\mathrm{mAb}$, monoclonal antibody; MMP, matrix metalloproteinase; PBS, phosphate-buffered saline

Key words: matrix metalloproteinases, MMP-2, MMP-9, tetraspanins, CD9 were not observed in immunoprecipitates of $\alpha 2-$ and $\beta 1-$ integrins, and tetraspanin CD9, an invasion and metastasis suppressor linked to integrins and FAK signaling. Our data demonstrate that the lateral redistribution and clustering of $\alpha 1$-integrins results in the recruitment of the FAK/src motilitypromoting signaling complex involved in cancer cell invasion. Disruption of this proinvasive pathway was accomplished by the dominant negative mutant of src (K295R, kinase dead), src pharmacological inhibitor (PP1) and $\alpha 1$-integrin function blocking antibodies. These findings support the notion that the $\alpha 1$-integrin- and src-dependent signalosome is a relevant therapeutic target against tumor progression in colon cancer patients.

\section{Introduction}

Invasion of cancer cells into surrounding tissues and distant organs is the most pejorative characteristic of malignant diseases associated with solid tumors and often results from aberrant signaling mechanisms. Unraveling signaling pathways that culminate in the invasive and metastatic phenotype is a major goal for understanding and combating cancer progression (1). The src tyrosine kinase, a member of the superfamily of membrane-associated non-receptor tyrosine kinases, is involved in multiple signal transduction pathways and cellular processes such as proliferation, adhesion, motility and survival (2-5). Oncogenic activation of the src tyrosine kinase is often observed at early and late stages of human colon cancer progression, from the adenoma to metastatic adenocarcinoma (6-8).

Despite intense research on src, the signaling mechanisms by which the src oncogene promotes cancer cell invasion remain elusive. Local and distant invasion of the surrounding extracellular matrix (ECM) network by cancer cells is predominantly mediated by integrins and other cell adhesion molecules. Most evidence that src is involved in integrin and focal adhesion (FAK) signals comes from studies showing the formation of molecular complexes containing $\mathrm{v}-\mathrm{Src}, \mathrm{FAK}$ and $B 1$-integrins at the focal adhesion platform linked to 
the actin cytoskeleton $(9,10)$. According to this model, FAK associates with various integrin subunits and becomes activated at Tyr397 upon integrin ligation. This family of heterodimeric $\alpha / \beta$ subunit receptors requires clustering of signaling proteins with integrin cytoplasmic domains to initiate downstream signaling events (11). Subsequent binding of FAK to src leads to the formation of an active and transient FAK-src signaling complex (12), that in turn promotes src-mediated phosphorylation of FAK within the kinase domain activation loop (Tyr576 and Tyr577), as well as phosphorylation of FAK at the C-terminal domain residues, Tyr861 and Tyr925 (13-15). Alternatively, src may directly associate with integrin $B$ tails. The activated FAK(Tyr397)/src signaling complex allows the activation of multiple downstream targets, including the mitogen-activated protein kinase (MAPK)-cascade through FAK925 tyrosine phosphorylation, p130Cas/Rac-mediated JNK activation via FAK Tyr861 or activation of paxillin by FAK Tyr576 and 577, in the kinase loop. This cascade is responsible for hyperphosphorylation of paxillin, and FAK, resulting in increased p130Cas activation (16-19) and activation of MMP-2 and MMP-9 (19-22). Increased expression and mutational activation of src has been reported in a subset of metastatic tumors (23), however, other mechanisms activating the src proto-oncogene including complex crosstalks with growth factor receptors and G-protein coupled receptors were also described $(24,25)$.

In the present study, we used the synthetic ether lipid analog ET-18-OMe (26) as a molecular probe to induce cellular invasion in order to explore the molecular mechanisms involved in the proinvasive response pathways in human colon cancer cells HCT-8/S11. This lipid analog was shown to induce loss of cell-cell adhesion and to stimulate invasion of MCF-7 breast cancer cells (27) through clustering of MSGb5 and activation of associated signaling molecules, FAK and src (28). We found here that ET-18-OMe selectively promotes the rapid clustering of $\alpha 1$-integrins, followed by the association and activation of a series of signaling elements in $\alpha 1$-integrin immunoprecipitates, namely FAK, src, p130Cas, and JNK, leading to enhanced secretion and activation of the MMP-2 and MMP-9 gelatinases.

\section{Materials and methods}

Antibodies and other reagents. Antibodies directed to $\alpha 1-$, $\alpha 2$ - and 31 -integrins and integrin $\alpha 1$ function blocking antibody were from Chemicon (Temecula, CA). Mouse anti-FAK and anti-src monoclonal antibodies ( $\mathrm{mAb}$ ) were from Transduction Laboratories (San Jose, CA). Rabbit anti-p-FAK Abs (Tyr398, Tyr576, Tyr861 and Tyr925) and anti-p-src (Tyr416) were from Biosource (Camarillo, CA). Rabbit anti-JNK, anti-pJNK (Thr183/Tyr185), anti-ERK, anti-p-ERK (Thr202/Tyr204) and anti-p-p130Cas (Tyr410) were obtained from Cell Signaling Technologies (Beverly, MA). Anti-paxillin, anti-ppaxillin and anti-p130Cas were from Chemicon. Antibodies to MMP-2 and MMP-9 were from Sigma (St. Louis, MO). Secondary biotinylated anti-rabbit and anti-mouse Abs were from Vector Laboratories (Burlingame, CA). The expression vector pSGT-src encoding the chicken src mutant K295R was a generous gift from Dr Serge Roche (CNRS UPR-1086 CRBM, Montpellier, France).
Cell culture and transfection. HCT-8/S11 human colon carcinoma cells were maintained at $37^{\circ} \mathrm{C}$ in RPMI buffer supplemented with $250 \mathrm{IU} / \mathrm{ml}$ penicillin, $100 \mathrm{mg} / \mathrm{ml}$ streptomycin, $100 \mathrm{mM}$ sodium pyruvate and $10 \%$ fetal bovine serum (FBS) (Invitrogen, Carlsbad, CA), in a humidified atmosphere containing $5 \% \mathrm{CO}_{2}$. HCT-8/S11 cells were cultured in the presence of $15 \mu \mathrm{g} / \mathrm{ml}$ ET-18-OMe (clinical grade), a generous gift from Dr P. Hilgard (Astra Medica, Frankfurt am Main, Germany). The src kinase inhibitor 4-amino-1-tert-butyl-3(1'-naphthyl) pyrazolo [3,4-d] pyrimidine (PP1) (Calbiochem, La Jolla, CA) was added at a final concentration of $20 \mu \mathrm{M}$. For expression of the dominant negative form of $\operatorname{src}(\mathrm{K} 295 \mathrm{R})$, HCT-8/S11 cells were plated for $24 \mathrm{~h}$ on $60-\mathrm{mm}$ diameter dishes and stably transfected by the Lipofectamine reagent and a mixture of $4 \mu \mathrm{g}$ of pSGT-src K295R and $0.4 \mu \mathrm{g}$ of pcDNA3 carrying the neomycin resistance gene. After $24 \mathrm{~h}$, cultures were split into 100-mm diameter dishes and selected for 14 days in $1 \mathrm{mg} / \mathrm{ml} \mathrm{G} 418$ (Invitrogen). Antibiotic-resistant colonies were ring-cloned as individual clones. Expression of the transgene was determined by Western blotting, using the anti-avian src mAb EC10 (Upstate Biotechnology). BCA protein assay reagent kit was from Pierce (Rockford, IL). Vectastain ABC-AmP kit was from Vector Laboratories. Drug toxicity was evaluated by measurement of mitochondrial dehydrogenase activities with MTT-reagent (Sigma) (29).

Collagen type I invasion and in-gel gelatinase assays. Sixwell plates were filled with $1.25 \mathrm{ml}$ neutralized type I collagen $(0.09 \%$, Upstate Biotechnology, Lake Placid, NY) and incubated for $1 \mathrm{~h}$ at $37^{\circ} \mathrm{C}$ to allow gelification. Single cell suspensions were prepared with trypsin/EDTA, mixed with or without ET-18-OMe and src kinase inhibitor (PP1), seeded on top of collagen type I gel and cultured at $37^{\circ} \mathrm{C}$ for $24 \mathrm{~h}$. Numbers of cells penetrating into gel or remaining at the surface were counted in 12 fields of $0.157 \mathrm{~mm}^{2}$, using an inverted microscope. The invasion index expresses the percentage of invading cells over the total number of cells.

Gelatin zymography was performed as described (30). Subconfluent cells were treated with ET-18-OMe and src kinase inhibitor PP1 in RPMI medium for $0,1,2,4,8$ and $12 \mathrm{~h}$ at $37^{\circ} \mathrm{C}$. The medium was collected, clarified by centrifugation, resolved in nonreducing gels containing gelatin $(2 \mathrm{mg} / \mathrm{ml})$ and processed for identification of gelatinase activity.

Western blotting. Cell lysates were made from $70 \%$ confluent cultures. Cells treated for the indicated times with ET-18-OMe and src kinase inhibitor, PP1 were washed three times with PBS and subsequently lysed in $0.5 \mathrm{ml}$ lysis buffer containing $1 \%$ Triton X-100, 1\% NP-40 and the following inhibitors: aprotinin $(10 \mu \mathrm{g} / \mathrm{ml})$, leupeptin $(10 \mu \mathrm{g} / \mathrm{ml}), \operatorname{PMSF}(1.72 \mathrm{mM})$, $\mathrm{NaF}(100 \mathrm{mM}), \mathrm{NaVO}_{3}(500 \mu \mathrm{M})$ and $\mathrm{Na}_{4} \mathrm{P}_{2} \mathrm{O}_{7}(500 \mu \mathrm{g} / \mathrm{ml})$. Aliquots of lysates containing the same quantity of proteins were boiled for $5 \mathrm{~min}$ in SDS-PAGE sample buffer containing $5 \%$ ß-mercaptoethanol, electrophoresed on 7.5\% SDS-PAGE and transferred to PVDF membranes (Immobilon-P) (Bio-Rad Laboratories, Hercules, CA). After transfer, membranes were incubated with relevant antibodies vs. FAK, p-FAK, src, p-src, ERK, p-ERK, MMP-2, MMP-9, integrins, p130Cas, pp130Cas, paxillin, p-paxillin, JNK and p-JNK followed by incubation with a secondary biotinylated antibody (1:1000) 
and developed by ECL (Vectastain ABC-AmP) detection kit. The membranes were stripped at $50^{\circ} \mathrm{C}$ for $30 \mathrm{~min}$ in $100 \mathrm{mM}$ ß-mercaptoethanol, 2\% SDS, $62.5 \mathrm{mM}$ Tris- $\mathrm{HCl}$ (pH 6.8), and reblotted with relevant antibodies. Membranes were imaged on the BioChemi System and analysis software (UVP, Upland, CA).

Immunoprecipitation of integrins. Association of integrins and signal transducers (FAK, src, p130Cas and JNK) was analyzed by immunoprecipitation. Cultured cancer cells at $70 \%$ confluency were treated for indicated times with ET18-OMe and subjected to lysis, as described above. Lysates, containing $800 \mu \mathrm{g}$ protein, were mixed with protein GSepharose beads (50 $\mu 1$, packed, Amersham Biosciences, $\mathrm{NJ}$ ) and placed on a rotator for $30 \mathrm{~min}$ at $4^{\circ} \mathrm{C}$, to preclear nonspecific binding. After centrifugation at $1,000 \mathrm{rpm}$ to collect the supernatant, $2 \mu \mathrm{l}$ of antibody was added and rotated at $4^{\circ} \mathrm{C}$ overnight. Subsequently, protein G-Sepharose beads were added, rotated at $4^{\circ} \mathrm{C}$ for $2 \mathrm{~h}$ and centrifuged to collect the beads. The beads were then washed twice with lysis buffer and the immunoprecipitates were resolved in $100 \mu 1$ SDS-PAGE sample buffer and heated to $95^{\circ} \mathrm{C}$ for $5 \mathrm{~min}$. The supernatants were subjected to SDS-PAGE, transferred electrophoretically to PVDF membranes, incubated with relevant antibodies and imaged and analyzed on the BioChemi System (UVP).

Fluorescence immunostaining. Cells were grown on glass cover slips (diameter, $12 \mathrm{~mm}$ ) placed in a 24-well plate. The cover glass with cells was removed, washed three times with ice-cold PBS and fixed with $3 \%$ paraformaldehyde. Fixed cells were washed three times with PBS, incubated with primary antibodies against integrins, followed by incubation with FITClabeled secondary antibodies. Stained cells were mounted with Glycergel mounting medium (Dako Corp., Carpinteria, CA) containing 1\% 1,4-diazabicyclo[2.2.2] octane (fluorescence stabilizer). Fluorescence was observed by fluorescence microscopy (Olympus IX51 with Olympus U-CMAD3 camera).

Statistics. All treatments were matched and carried out at least 3 times. The Student t-test (95\%) was used for statistical evaluation. Intensity of immunoblotted bands was quantified by densitometry, using statistical software Scion Image (Scion Corporation, Frederick, MD).

\section{Results}

Activation of src and cellular invasion in human colon cancer cells. As shown in Fig. 1A, ET-18-OMe promoted invasion into collagen type I in parental HCT-8/S11 cells, but not in their HCT-8/S11DnSrc counterparts, stably transfected by the dominant-negative mutant of src. Similarly, pretreatment of HCT-8/S11 cells with the src kinase inhibitor PP1, blocked ET-18-OMe-induced invasion into collagen type I. We found that ET-18-OMe induced a rapid (5 min) and persistent activation of src in HCT-8/S11 cells that was abolished by the src inhibitor PP1 (Fig. 1B). As expected, no altered src kinase activity was observed in ET-18-OMe treated HCT-8/ S11DnSrc cells. Taken together, our data indicate that the src kinase is involved in the ET-18-OMe-induced invasion.
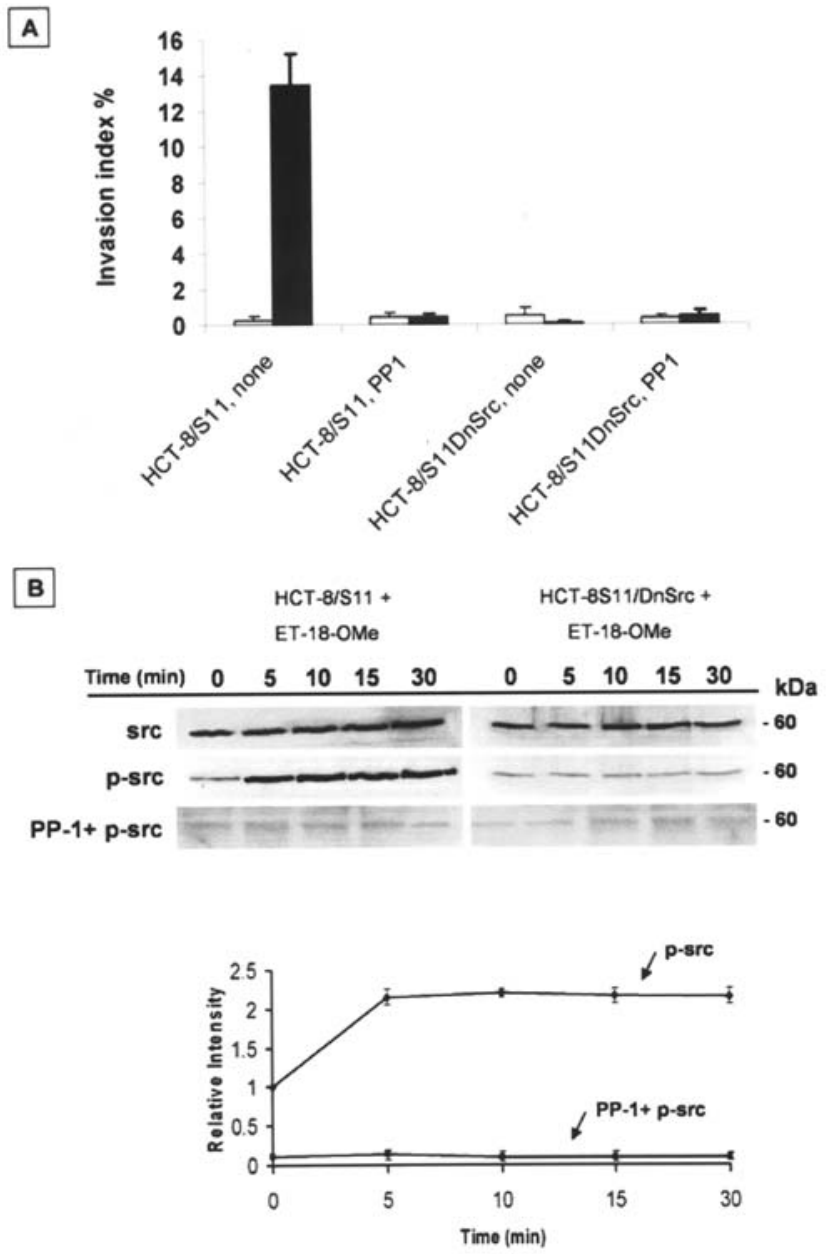

Figure 1. Induction of cancer cell invasion and src activation. (A) Effect of ET-18-OMe (black columns) on the invasion of type I collagen by parental HCT-8/S11 and HCT-8/S11DnSrc colon cancer cells stably transfected by the dominant negative mutant K295R of src. Where indicated, parental and DnSrc cells were incubated in the presence or absence (none) of the src kinase inhibitor PP1. (B) Western blot analysis of phosphorylated and activated src (p-src) at Tyr416. Cell lysates $(30 \mu \mathrm{g})$ from parental and DnSrc cells treated for indicated times with ET-18-OMe or ET-18-OMe plus PP1 were analyzed by $7.5 \%$ SDS-PAGE, using the corresponding primary antibodies. The membranes were reblotted after stripping with anti-src for total src expression and protein loading. Bottom, densitometric band analysis corresponding to phosphorylated src (p-src, Tyr416), versus total src (relative intensity). All data are means \pm SEM from three experiments.

Implication of src in phosphorylation sites in FAK. To determine the role of src and FAK in ET-18-OMe-induced invasion, we examined the status of FAK phosphorylation at Tyr397, the FAK autophosphorylation and activation site, as well as the other FAK tyrosine residues (Tyr576, Tyr861, Tyr925) in HCT-8/S11 and HCT-8/S11DnSrc cells. As shown in Fig. 2, activity of FAK Tyr397 was greatly enhanced in HCT-8/S11 and slightly increased in HCT-8/ S11DnSrc after 5-10 min of ET-18-OMe treatment. The inhibitor, PP1, partially blocked activation of FAK Tyr397 in HCT-8/S11. Timedependent phosphorylation of FAK on Tyr576 and Tyr861 but not Tyr925 was observed in ET-18-OMe-treated HCT-8/ $\mathrm{S} 11$ cells and no alteration in phosphorylation of either tyrosine residues was detected in HCT-8/S11DnSrc cells. Furthermore, inhibition of src prevented FAK phosphorylation at Tyr576 and Tyr861 (Fig. 2). 

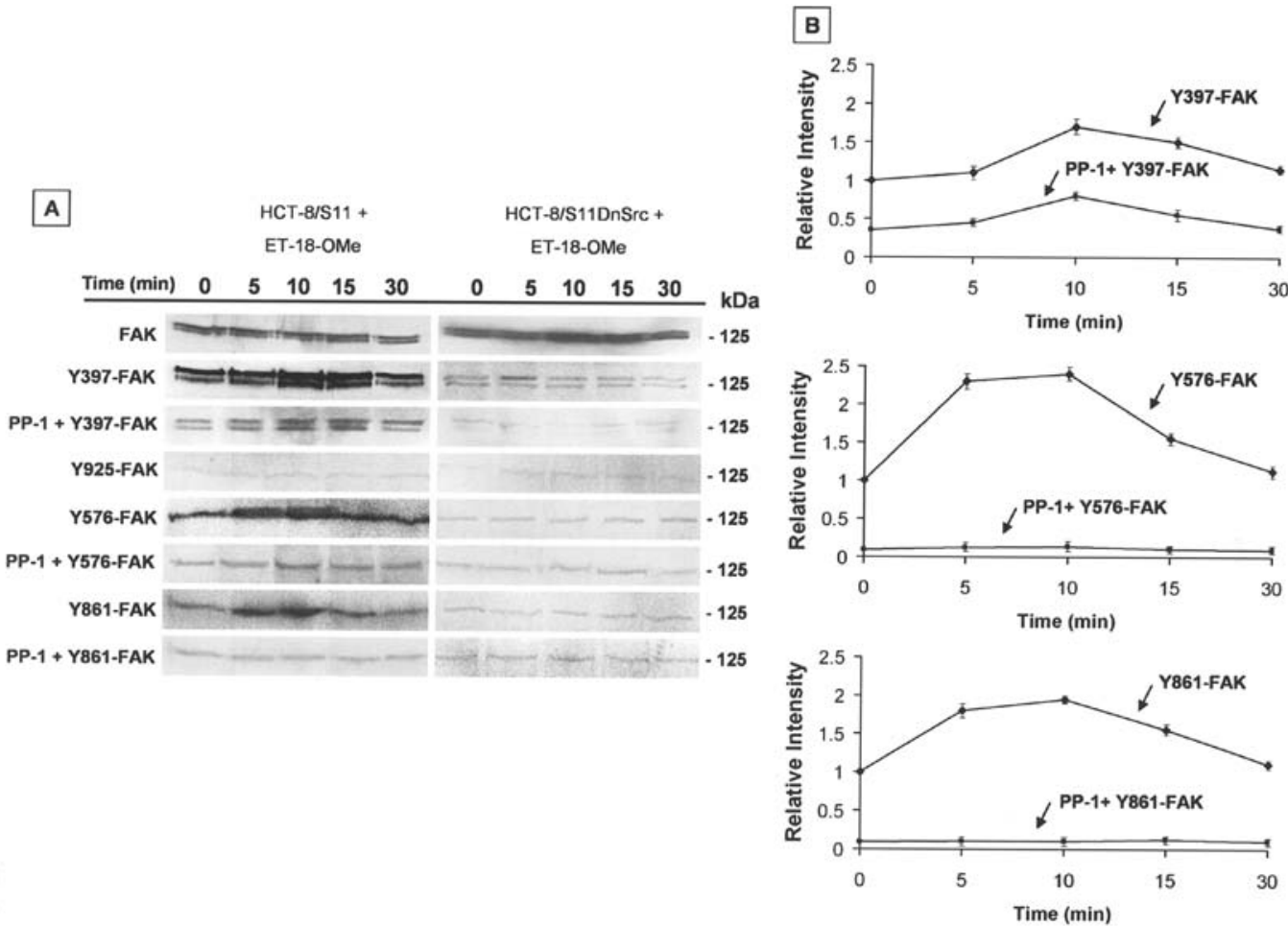

Figure 2. Phosphorylation and activation of the FAK phosphorylation sites. (A) Western blot analysis of phosphorylated and activated FAK (p-FAK) at Tyr397-Tyr576-Tyr861 and Tyr925. Cell lysates (30 $\mu \mathrm{g}$ ) prepared from parental and DnSrc HCT-8/S11 cells treated for indicated times with ET-18-OMe or ET-18-OMe plus PP1 were analyzed by 7.5\% SDS-PAGE, using the corresponding primary antibodies. The membranes were reblotted after stripping with anti-FAK for total FAK expression and protein loading. (B) Densitometric band analysis corresponding to p-FAK (Tyr397, Tyr576, and Tyr861) versus total protein in the cell lysates (relative intensity). All data are means \pm SEM from three experiments.

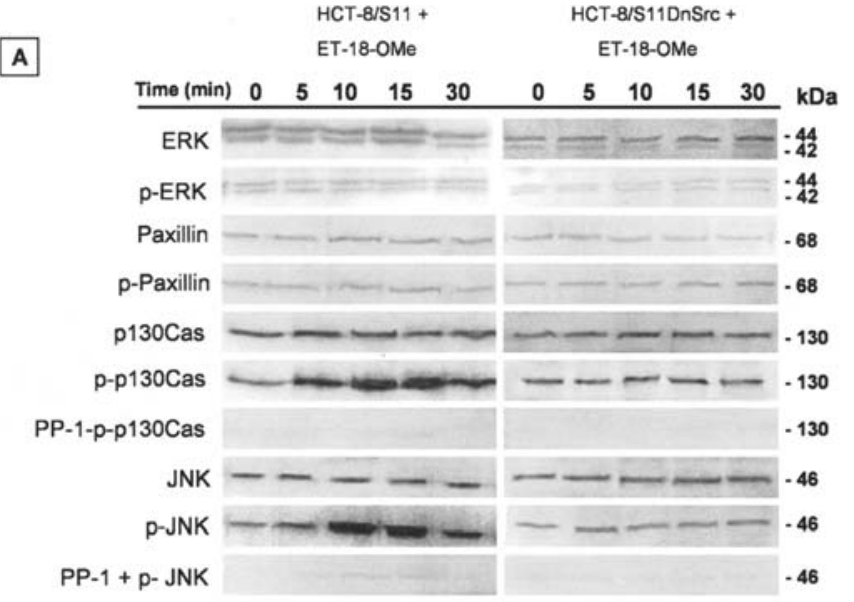

B

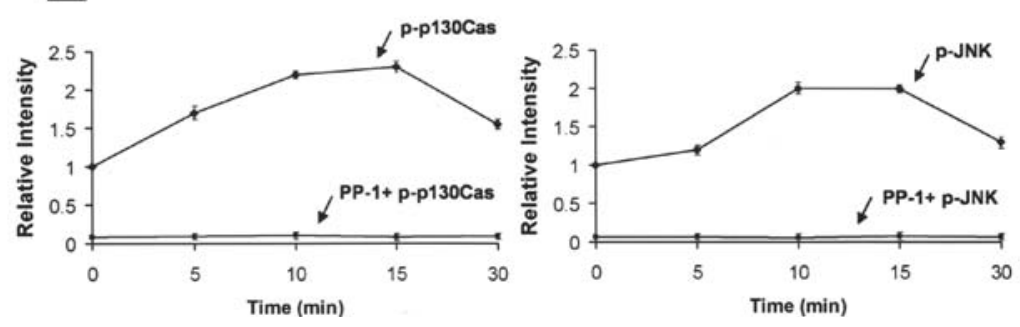

Figure 3. Phosphorylation and activation of p130Cas and JNK. (A) Western blot analysis of phosphorylated and activated p42/p44 ERK (p-ERK, Thr202/Tyr204), paxillin (p-paxillin, Tyr118), p130Cas (p-p130Cas, Tyr410) and JNK (p-JNK, Thr183/Tyr185). Cell lysates (30 $\mu$ g) prepared from HCT-8/ S11 and HCT-8/S11DnSrc cells treated for indicated times with ET-18-OMe or ET-18-OMe plus PP1, were analyzed by 7.5\% SDS-PAGE, as indicated above. The membranes were re-blotted with anti-ERK, anti-paxillin, anti-p130Cas and anti-JNK after stripping. (B) Densitometric band analysis corresponding to phosphorylated p130Cas (p-p130Cas, Tyr410) and JNK (p-JNK, Thr183/Tyr185), versus total proteins in the cell lysates (relative intensity). All data are means \pm SEM from three experiments. 


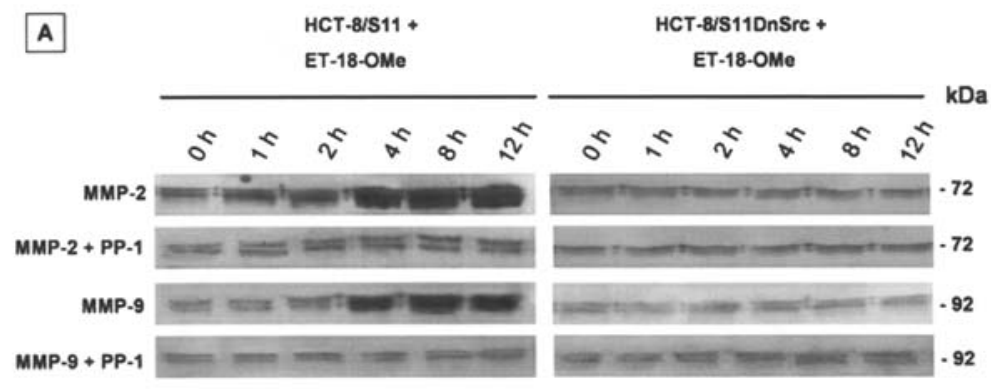

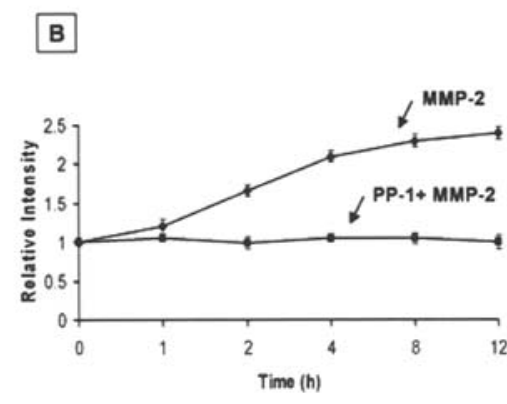

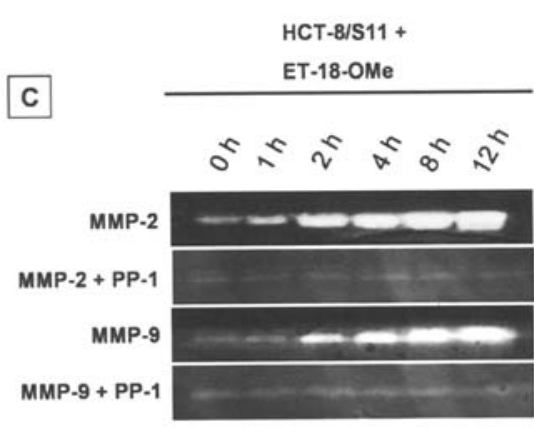

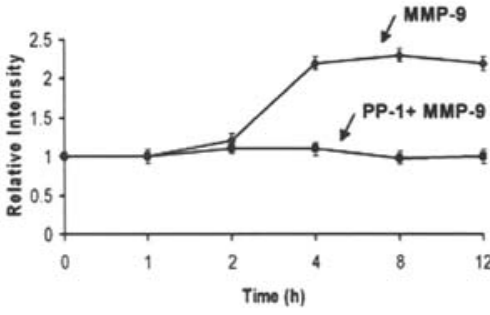

HCT-8/S11DnSrc + ET-18-OMe

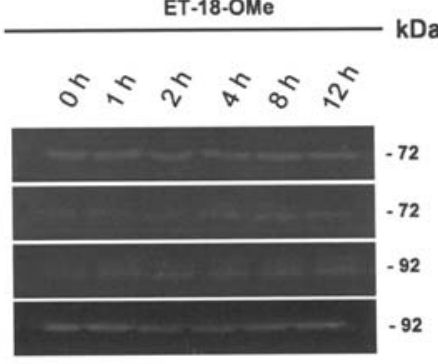

D
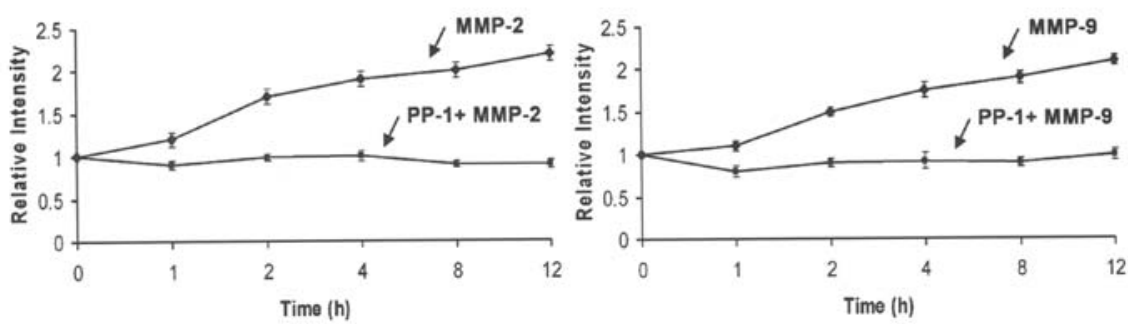

Figure 4. Functional induction of the matrix metalloproteinases MMP-2 and -9. (A) Western blot analysis of MMP-2 and MMP-9 expression. Cell lysates (30 $\mu \mathrm{g}$ ) prepared from parental and DnSrc HCT-8/S11 cells treated for the indicated times with ET-18-OMe or ET-18-OMe plus PP1 were analyzed by 7.5\% SDSPAGE. (B) Densitometric analysis of the MMP-2 and MMP-9 bands detected in cell lysates. (C) Activity of MMP-2 and MMP-9 metalloproteinases by gelatin zymography in parental and DnSrc HCT-8/S11 cells after treatment with ET-18-OMe for the indicated times. Conditioned media prepared from subconfluent cultures were collected, resolved in nonreducing gels containing gelatin $(2 \mathrm{mg} / \mathrm{ml})$ and processed for zones of gel degradation activity. (D) Densitometric band analysis of the corresponding activities by zymography. All data are means \pm SEM from three experiments.

Implication of p130Cas and JNK downstream src and FAK activation. The src-FAK signaling complex activates multiple downstream signaling elements via distinct tyrosine residues on FAK (31). Phosphorylation at Tyr576 in the kinase activation loop led to hyperphosphorylation of paxillin (32), while Tyr861 phosphorylation has been linked to JNK activation via p130Cas $(33,34)$. As shown in Fig. 3, ET-18-OMe enhanced the phosphorylation status of p130Cas and JNK in HCT-8/S11 cells. Both DnSrc and PP1 abolished these cellular responses. As expected, ET-18-OMe did not alter the phosphorylation and activation levels of ERK, in agreement with the unchanged phosphorylation levels of FAK at Tyr925, the phosphorylation site linked to the p42/p44 MAPK signaling pathway (16).

Implication of MMP-2 and MMP-9 downstream src activation. Since JNK has been considered a Ser/Thr kinase linked to MMP regulation (19-22), we investigated the impact of ET18-OMe on the expression and activation status of MMP-2 and MMP-9 in HCT-8/S11 cells. As shown in Fig. 4, MMP-2 and MMP-9 protein levels were greatly enhanced in HCT-8/ $\mathrm{S} 11$ cells following the addition of ET-18-OMe for 4-12 h. 

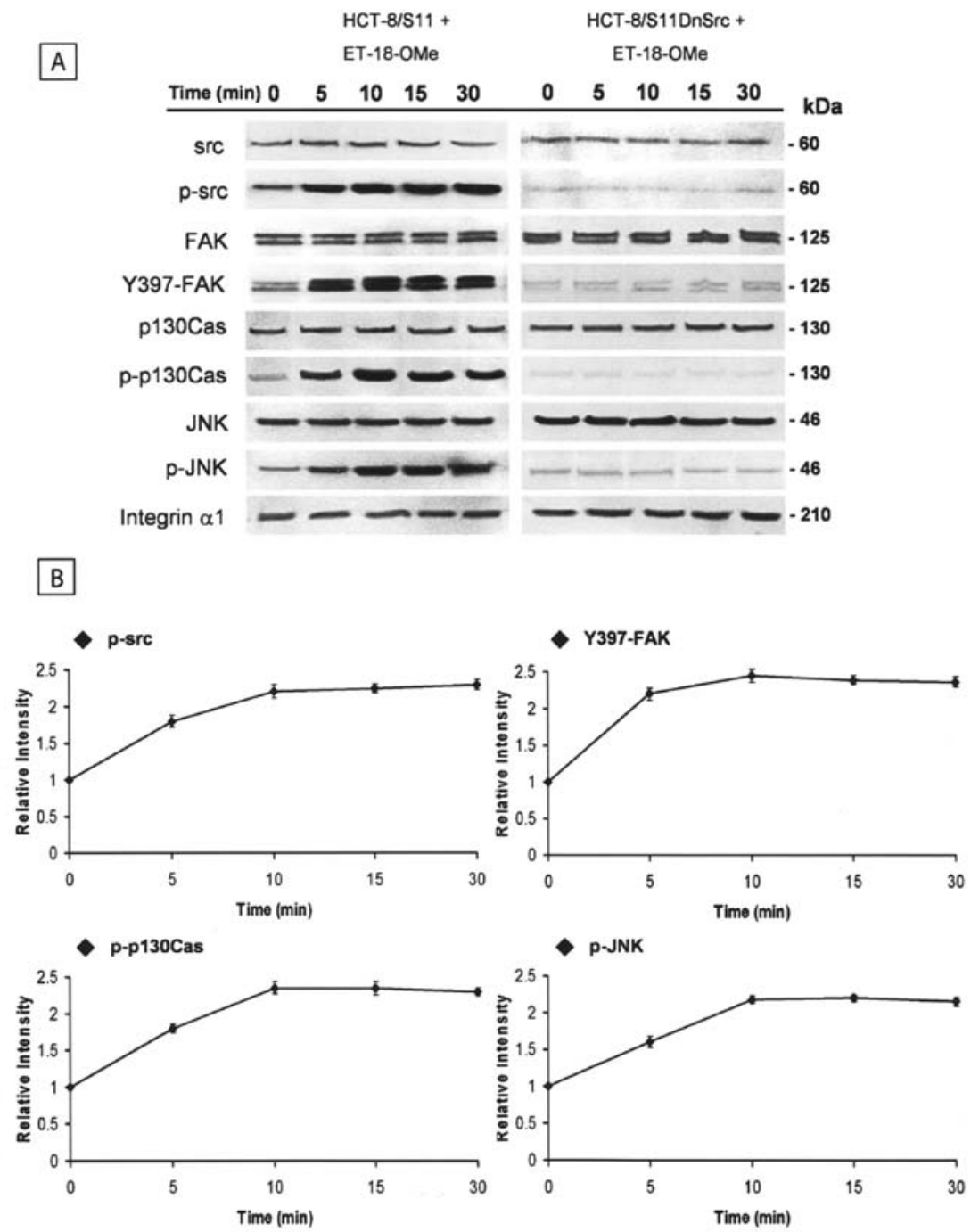

Figure 5. Clustering and activation of signaling intermediates in $\alpha 1$-integrin immunoprecipitates. (A) Association of activated src (p-src, Tyr416), FAK (p-FAK, Tyr397), p130Cas (p-130Cas, Tyr410) and JNK (p-JNK, Thr183/Tyr185) in $\alpha 1$-integrin immunoprecipitates prepared from control cells and DnSrc HCT-8/S11 cells incubated in the presence or absence of ET-18-OMe for the indicated times. Aliquots of immunoprecipitates were then analyzed by direct Western blotting using the respective antibodies. (B) Densitometric band analysis corresponding to phosphorylated src (p-src, Tyr416), FAK (p-FAK, Tyr397), p130Cas (p-130Cas, Tyr410), and JNK (p-JNK, Thr183/Tyr185), versus total proteins in the $\alpha 1$-integrin immunoprecipitates (relative intensity). All data are means \pm SEM from three experiments.

Interestingly, the activity of these two MMPs significantly increased in HCT-8/S11 cells treated with ET-18-OMe (Fig. 4C and D). MMP protein induction and activation were abrogated following src inhibition with either PP1 or DnSrc cells.

Clustering of integrins and activation of associated signal transducers. Since src and FAK are recognized as two critical mediators of integrin signaling, we addressed the question whether $\alpha 1-, \alpha 2$ - and $\beta 1$-integrins were implicated in ET-18OMe-induced activation of FAK and its associated downstream elements involved in collagen type I invasion and MMP activation by cancer cells. These integrins $\alpha 1, \beta 1$ and $\alpha 2$ are the major collagen receptors binding collagen type I in extracellular matrix. Activation of this signaling cascade has been ascribed to the clustering of integrins with associated FAK signaling elements (35). We first examined integrin clustering by immunofluorescence microscopy. HCT-8/S11 cells revealed a selective $\alpha 1$-integrin clustering 10-30 min after the addition of ET-18-OMe since no clustering was detected for $\alpha 2-$ and B1-integrins (not shown). Interestingly, ET-18-OMe-induced integrin $\alpha 1$ clustering was not impaired by src inhibition in HCT-8/S11DnSrc cells.

We next examined the effect of ET-18-OMe on the FAKassociated signaling molecules src, p130Cas and JNK in $\alpha 1-$ and $\alpha 2$-integrin immunoprecipitates. As shown in Fig. 5, activated forms of src (Tyr416), FAK (Tyr397), p130Cas and JNK were found in $\alpha 1$-integrin immunoprecipitates prepared from parental HCT-8/S11 cells treated for 5-15 min with ET-18-OMe. This response was abolished in DnSrc cells (Fig. 5A, right) and was not observed in $\alpha 2$ - and 31 -integrin immuno-precipitates (not shown).

\section{Discussion}

The non-receptor tyrosine kinase src was described to play key roles in signal transduction following transient activation by a vast array of cell surface receptors and signaling pathways using receptor and non-receptor tyrosine kinases, G-protein coupled receptors, and integrins in normal epithelial cells (36). When activated, integrins associate with the src SH3 domain, 
thereby unmasking the catalytic domain and activating src. Activated src, in turn, regulates integrin-cytoskeleton functions and dissociation of the E-cadherin/ß-catenin complex in the context of cellular motility, scattering and invasion $(37,38)$. Immediate responses mediated by integrins and src include cellular adhesion, migration, and activation of the actin cytoskeleton. In addition, delayed responses controlled by src are associated with cell survival and transcriptional activation of transformation-related genes via STAT-3 and AP-1 signaling pathways $(39,40)$. Furthermore, increased src expression and constitutive tyrosine phosphorylation are frequently observed at early and late stages of colon cancer progression, and these changes correlate with cancer cell metastasis in human solid tumors $(2,5,8)$.

ET-18-OMe, an analog of the naturally occurring 2-lysophosphatidylcholine (2-LPC), induces loss of cell-cell adhesion and stimulates invasion of human MCF-7 breast cancer cells, through sterical hindrance of the E-cadherin tumor suppressor by episialin/MUC-1 (27). In the present study, we add further evidence that ET-18-OMe promotes invasion into collagen type I, via integrin-mediated FAK and src signaling pathways in human colon cancer cells HCT-8/S11. Whereas previous studies have implicated the FAK-src signaling complex and B1-integrins in cellular invasion (10), our studies support a role for $\alpha 1$-integrins in collagen type I invasion, since blocking the function of $\alpha 1$-integrins inhibited the ET-18-OMe-induced invasion into collagen type I (not shown). This effect was mediated through membrane redistribution of $\alpha 1$-integrins and clustering with their associated proteins FAK/src and p130Cas/JNK, under activated forms. Similar clustering of the integrin subunits $\beta 1$ and $\alpha 2$ could not be detected nor any association between $\beta 1$ - and $\alpha 2$-integrins with these signaling molecules. Integrin $\alpha 1$ clustering and binding of FAK to the integrin $\alpha 1$ subunit is critically important for activation of intracellular responses (35) and results in enhanced integrindependent phosphorylation of FAK (41). The recruitment and clustering of integrins and activation of signaling pathways are often regulated by glycosphingolipids or glycosphingolipidenriched microdomain components (42-44) and thus influence integrin engagement and functions (45). These membrane microdomains integrate proteins involved in vesicular trafficking and signal transduction, including src and FAK, G-proteins, receptor tyrosine kinases (EGF-R, PDGF-R), and serve as molecular platforms for signaling processes (46). However, we found that integrin clustering and the FAK/src signaling involved in the ET-18-OMe-mediated invasive process does not occur through plasma membrane microdomains and is not associated with individual glycosphingolipids in these subcellular fractions (not shown). Conversely, exclusion of signaling molecules from membrane microdomains may also regulate signal transduction (47).

We have shown here that ET-18-OMe caused prompt clustering of integrin $\alpha 1$ and coclustering with FAK and src, resulting in increased phosphorylation levels of FAK at Tyr397, Tyr576 and Tyr861 in HCT-8/S11 cells. The src inhibitors, PP1 and DnSrc, markedly decreased the phosphorylation levels at Tyr576 and Tyr861, while Tyr397 phosphorylation was only partially reduced. Consequently, FAK phosphorylation at Tyr397 led to the formation of the src/FAK dual kinase complex with maximal activation of FAK through src- dependent phosphorylation of Tyr576 in the FAK activation loop. In addition, our results revealed that ET-18-OMe initiated specific downstream signaling events via Tyr861 since no changes were observed in FAK phosphorylation at Tyr925, a FAK domain linked to ERK activation (16). In agreement, both ERK and paxillin were found under inactivated forms in ET-18-OMe-treated cells (32). Furthermore, we showed that ET-18-OMe induced src-dependent tyrosine phosphorylation of the src substrate p130Cas associated with FAK phosphorylation at Tyr861, which subsequently led to JNK activation and increased expression and activation of MMP-2 and MMP-9. Our data are coherent with previous studies on integrin- and src-dependent signaling in cellular invasion via enhanced MMP expression and secretion (9,19-22,33-35). In contrast, we found that CD9 immunoprecipitates prepared from ET18-OMe-treated HCT-8/S11 cells contained src and JNK under non-activated forms (not shown). Consistent with our finding, the CD9 tetraspanin protein was shown to inhibit MMP-2 production and to suppress cancer cell invasion and metastasis, through molecular complex formation with $\alpha 3 / 31$ integrins in human solid tumors $(48,49)$.

Taken together, we provide here the first evidence that the engagement of $\alpha 1$-integrins with functional molecular scaffolds using FAK/src and p130Cas/JNK is involved in cancer cell invasion through the induction and activation of the MMP-2 and MMP-9 matrix metalloproteinases. Thus, additional transcriptional pathways activated downstream $\alpha 1$ integrins and src/JNK might be at least responsive in part for the increased levels of MMP-2 and MMP-9 (40). Consistent with this model, these signaling pathways are connected with decision points governing cell adhesion, responses to cellular stress, survival and invasive growth that integrate the molecular and cellular mechanisms involved in the metastatic cascade. Targeting these signaling elements by therapeutic agents may bring additional strategies to control the neoplastic progression. The rationale of this strategy has been recently presented for targeting $\alpha 1 \beta 1$ integrins receptors and Sema7A signaling in clinical symptoms of chronic inflammatory diseases (50) which ultimately could lead to malignant progression.

\section{Acknowledgements}

This study was supported by the US National Institutes of Health (RR-16480) under the BRIN/INBRE program of the National Center for Research Resources, the New Mexico Tech startup funds, INSERM, and a Research Grant from ARC.

\section{References}

1. Christofori G: New signals from the invasive front. Nature 441: 444-450, 2006.

2. Thomas SM and Brugge JS: Cellular functions regulated by Src family kinases. Annu Rev Cell Dev Biol 13: 513-609, 1997.

3. Schwartzberg PL: The many faces of Src: multiple functions of a prototypical tyrosine kinase. Oncogene 17: 1463-1468, 1998.

4. Frame MC: Newest findings on the oldest oncogene; how activated src does it. J Cell Sci 117: 989-998, 2004.

5. Alper O and Bowden ET: Novel insights into src. Curr Pharm Des 11: 1119-1130, 2005.

6. Bolen JB, Veillette A, Schwartz AM, DeSeau V and Rosen N: Activation of pp60src protein kinase activity in human colon carcinoma: Proc Natl Acad Sci USA 84: 2251-2255, 1987.

7. Cartwright CA, Kamps MP, Meisler AI, Pipas JM and Eckhart W: pp60src activation in human colon carcinoma. J Clin Invest 83: 2025-2033, 1989. 
8. Talamonti MS, Roh MS, Curley SA and Gallick GE: Increase in activity and level of pp60src in progressive stages of human colorectal cancer. J Clin Invest 91: 53-60, 1993.

9. Hauck CR, Hsia DA, Puente XS, Cheresh DA and Schlaepfer DD: FRNK blocks v-Src-stimulated invasion and experimental metastases without effects on cell motility or growth. EMBO J 21: 6289-6302, 2002.

10. Hauck CR, Hsia DA, Ilic D and Schlaepfer DD: v-Src SH3enhanced interaction with focal adhesion kinase at $\beta 1$ integrincontaining invadopodia promotes cell invasion. J Biol Chem 277: 12487-12490, 2002

11. Schwartz MA: Integrin signaling revisited. Trends Cell Biol 11: 466-470, 2001.

12. Schaller MD, Hildebrand JD, Shannon JD, Fox JW, Vines RR and Parsons JT: Autophosphorylation of the focal adhesion kinase, pp125FAK, directs SH2-dependent binding of pp60src. Mol Cell Biol 14: 1680-1688, 1994.

13. Calalb MB, Zhang X, Polte TR and Hanks SK: Focal adhesion kinase tyrosine- 861 is a major site of phosphorylation by Src. Biochem Biophys Res Commun 228: 662-668, 1996.

14. Calalb MB, Polte TR and Hanks SK: Tyrosine phosphorylation of focal adhesion kinase at sites in the catalytic domain regulates kinase activity: a role for Src family kinases. Mol Cell Biol 15: 954-963, 1995.

15. Schlaepfer DD and Hunter T: Evidence for in vivo phosphorylation of the Grb2 SH2-domain binding site on focal adhesion kinase by Src-family protein-tyrosine kinases. Mol Cell Biol 16: 5623-5633, 1996.

16. Schlaepfer DD, Jones KC and Hunter T: Multiple Grb2mediated integrin-stimulated signaling pathways to ERK2/ mitogen-activated protein kinase: summation of both src and focal adhesion kinase-initiated tyrosine phosphorylation events. Mol Cell Biol 18: 2571-2585, 1998

17. Petit V, Boyer B, Lentz D, Turner CE, Thiery JP and Valles AM: Phosphorylation of tyrosine residues 31 and 118 on paxillin regulates cell migration through and association with CRK in NBT-II cells. J Cell Biol 148: 957-970, 2000.

18. Valles AM, Beuvin M and Boyer B: Activation of Rac1 by Paxillin-Crk-Dock180 signaling complex is antagonized by Rap1 in migrating NBT-II cells. J Biol Chem 279: 44490-44496, 2004.

19. Hsia DA, Mitra SK, Hauck CR, et al: Differential regulation of cell motility and invasion by FAK. J Cell Biol 160: 753-767, 2003.

20. Kurata H, Thant AA, Matsuo S, Senga T, Okazaki K, Hotta N and Hamaguchi M: Constitutive activation of MAP kinase kinase (MEK1) is critical and sufficient for the activation of MMP-2. Exp Cell Res 254: 180-188, 2000

21. Shin M, Yan C and Boyd D: An inhibitor of c-jun aminoterminal kinase (SP600125) represses c-jun activation, DNA binding and PMA-inducible 92-kDa type IV collagenase expression. Biochim Biophys Acta 1589: 311-316, 2002.

22. Brabek J, Constancio SS, Siesser PF, Shin NY, Pozzi A and Hanks SK: Crk-associated substrate tyrosine phosphorylation sites are critical for invasion and metastasis of SRC-transformed cells. Mol Cancer Res 3: 307-315, 2005.

23. Irby RB, Mao W, Coppola D, et al: Activating SRC mutation in a subset of advanced human colon cancers. Nat Genet 21: 187-190, 1999

24. Mao W, Irby R, Coppola D, et al: Activation of src by receptor tyrosine kinases in human colon cancer cells with high metastatic potential. Oncogene 15: 3083-3090, 1997.

25. Jones RJ, Avizienyte E, Wyke AW, Owens DW, Brunton VG and Frame MC: Elevated src is linked to altered cell-matrix adhesion rather than proliferation in KM12C human colorectal cancer cells. Br J Cancer 87: 1128-1135, 2002.

26. Steelant WF, Recchi MA, Noe VT, et al: Elevated src is linked to altered cell-matrix adhesion rather than proliferation in $\mathrm{KM} 12 \mathrm{C}$ human colorectal cancer cells. Clin Exp Metastasis 17: 245-253, 1999.

27. Steelant WF, Goeman JL, Philippe J, et al: Alkyl-lysophospholipid 1-O-octadecyl-2-O-methyl-3 glycerophosphocholine induces invasion through episialin-mediated neutralization of $\mathrm{E}$ cadherin in human mammary MCF-7 cells in vitro. Int J Cancer 92: 527-536, 2001

28. Van Slambrouck S and Steelant WF: Clustering of monosialylGb5 initiates downstream signaling events leading to invasion of MCF-7 breast cancer cells. Biochem J 401: 689-699, 2007.

29. Romijn JC, Verkoelen CF and Schroeder FH: Application of the MTT assay to human prostate cancer cell lines in vitro: establishment of test conditions and assessment of hormone- stimulated growth and drug-induced cytostatic and cytotoxic effects. Prostate 12: 99-110, 1988.

30. Brown PD, Levy AT, Margulies IM and Liotta LA, Stetler-Stevenson WG: Independent expression and cellular processing of Mr 72,000 type IV collagenase and interstitial collagenase in human tumorigenic cell lines. Cancer Res 50: 6184-6191, 1990.

31. Schlaepfer DD and Mitra SK: Multiple connections link FAK to cell motility and invasion. Curr Opin Genet Dev 14: 92-101, 2004.

32. Gabarra-Niecko V, Keely PJ and Schaller MD: Characterization of an activated mutant of focal adhesion kinase: 'SuperFAK'. Biochem J 365: 591-603, 2002

33. Lim Y, Han I, Jeon J, Park H, Bahk YY and Oh ES : Phosphorylation of focal adhesion kinase at tyrosine 861 is crucial for Ras transformation of fibroblasts. J Biol Chem 279: 29060-29065, 2004.

34. Dolfi F, Garcia-Guzman M, Ojaniemi M, Nakamura H, Matsuda $\mathrm{M}$ and Vuori K: The adaptor protein Crk connects multiple cellular stimuli to the JNK signaling pathway. Proc Natl Acad Sci USA 95: 15394-15399, 1998.

35. Miyamoto S, Teramoto H, Coso OA, Gutkind JS, Burbelo PD, Akiyama SK and Yamada KM: Integrin function: molecular hierarchies of cytoskeletal and signaling molecules. J Cell Biol 131: 791-805, 1995

36. Ma YC, Huang J, Ali S, Lowry W and Huang XY: The adaptor protein Crk connects multiple cellular stimuli to the JNK signaling pathway. Cell 102: 635-646, 2000.

37. Behrens J, Vakaet L, Friis R, Winterhager E, Van Roy F, Mareel MM and Birchmeier W: Loss of epithelial differentiation and gain of invasiveness correlates with tyrosine phosphorylation of the E-cadherin/beta-catenin complex in cells transformed with a temperature-sensitive v-SRC gene. J Cell Biol 120: 757-766, 1993.

38. Empereur S, Djelloul S, Di Gioia Y, et al: Progression of Familial Adenomatous Polyposis (FAP) colonic cells after transfer of the src or polyoma middle $\mathrm{T}$ oncogenes. Cooperation between src and HGF/Met in invasion. Br J Cancer 75: 241-250, 1997.

39. Turkson J, Bowman T, Garcia R, Caldenhoven E, De Groot RP and Jove R: Stat 3 activation by Src induces specific gene regulation and is required for cell transformation. Mol Cell Biol 18: 2545-2552, 1998

40. Rivat C, Le Floch N, Sabbah M, et al: Synergistic cooperation between the AP-1 and LEF-1 transcription factors in the activation of the matrilysin promoter by the src oncogene: implications in cellular invasion. Faseb J 17: 1721-1723, 2003.

41. Loster K, Vossmeyer D, Hofmann W, Reutter W and Danker K : Stat 3 activation by Src induces specific gene regulation and is required for cell transformation. Biochem J 356: 233-240, 2001.

42. Brown DA and London E: Structure and function of sphingolipid- and cholesterol-rich membrane rafts. J Biol Chem 275: 17221-17224, 2000.

43. Mitchell JS, Kanca O and McIntyre BW: Lipid microdomain clustering induces a redistribution of Antigen recognition and adhesion molecules on human T-lymphocytes. J Immunol 168: 2737-2744, 2002

44. Toledo MS, Suzuki E, Handa K and Hakomori S: Effect of ganglioside and tetraspanins in microdomains on interaction of integrins with fibroblast growth factor receptor. J Biol Chem 280: 16227-16234, 2005

45. Sharma DK, Brown JC, Cheng Z, Holicky EL, Marks DL and Pagano RE: The glycosphingolipid, lactosylceramide, regulates B1-integrin clustering and endocytosis. Cancer Res 65: 8233-8241, 2005 .

46. Simons K and Toomre D: Lipid rafts and signal transduction: Nat Rev Mol Cell Biol 1: 31-39, 2000.

47. Janes PW, Ley SC and Magee AI: Aggregation of lipid rafts accompanies signaling via the $\mathrm{T}$ cell antigen receptor. J Cell Biol 147: 447-461, 1999.

48. Saito Y, Tachibana I, Takeda Y, et al: Absence of CD9 enhances adhesion-dependent morphologic differentiation, survival, and matrix metalloproteinase-2 production in small cell lung cancer cells. Cancer Res 66: 9557-9565, 2006.

49. Sugiura $T$ and Berditchevski F: Function of alpha3 beta1tetraspanin protein complexes in tumor cell invasion. Evidence for the role of the complexes in production of matrix metalloproteinase 2 (MMP-2). J Cell Biol 146: 1375-1389, 1999.

50. Suzuki K, Okuno T, Yamamoto M, et al: Semaphorin 7A initiates T-cell-mediated inflammatory responses through $\alpha 1 \beta 1$ integrin. Nature Published online 21 March 2007. 